\title{
ACKNOWLEDGMENTS
}

THIS BOOK COULD NEVER have been completed without the guidance, love, and encouragement of my friends and colleagues. Thank you all for participating in this collective process. I want to thank Mare Schumacher, my life partner, for her unwavering support. Her willingness to tolerate seemingly endless hours at the computer obsessing over a particular turn of phrase is deeply appreciated. Her edits, insights, and recommendations for this book were priceless. There is not enough I can do to thank her.

I am also indebted to Cecilia Menjivar. Her subtle suggestions at the start of my research made all the difference. Thank you, Randy Hanson, for lifting the curtain and showing me the wizard, reminding me that there is much beyond academia. To Beth Swadener, thank you for being an inspiration and a mentor on how to be a true scholar/activist. Also, thanks to the Society for the Study of Social Problems (and all its members) for financially supporting my research and providing an atmosphere that makes critical scholarship possible. Finally, thanks to Ray Michalowski and Adi Hovav for making editorial suggestions that greatly improved the manuscript.

A special thanks goes to Sue Hilderbrand, who ran with me in movement and stood by me when my fears got the best of me. Thanks also to Amory Starr for supporting my work. Her mentoring has been valuable. Likewise, Emily Gaarder and Randall Amster were wonderful sounding boards, providing insightful personal and intellectual feedback. In addition, my parents, Luis and Hada Luz Fernandez, played a central role 
getting me this far. Without their life lessons and constant emotional support, none of this would have been possible. Last (and definitely not least), I'd like to thank Rafiki and Chyna, two of the best dogs in the world. Thank you all very much. My love for all of you is unending and my appreciation deeply felt. 


\section{Policing Dissent}


